NOTE

\title{
Genetic diversity among A-proteins of atypical strains of Aeromonas salmonicida
}

\author{
Vera Lund*, Helene Mikkelsen \\ Fiskeriforskning, Norwegian Institute of Fisheries and Aquaculture Research, 9291 Tromsø, Norway
}

\begin{abstract}
The virulence array protein gene A (vapA) encoding the A-protein subunit of the surface layer of 23 typical and atypical strains of Aeromonas salmonicida from salmonids and marine fish species were sequenced, and the deduced A-protein sequences compared. The A-proteins of the typical A. salmonicida ssp. salmonicida strains were shown to be identical, while amino acid variability was revealed among A-proteins of atypical strains. The highest amino acid variability appears to be in a predicted surface exposed region and is believed to result in antigenic differences among the atypical strains of $A$. salmonicida.
\end{abstract}

KEY WORDS: Atypical Aeromonas salmonicida · A-protein sequence · Surface A-layer

Resale or republication not permitted without written consent of the publisher

Aeromonas salmonicida ssp. salmonicida is referred to as typical $A$. salmonicida and causes furunculosis mostly in salmonid fish, while atypical A. salmonicida strains including ssp. achromogenes, masoucida, smithia and pectinolytica (Smith 1963, Kimura 1969, Austin et al. 1989, Pavan et al. 2000) cause ulcerative diseases or atypical furunculosis in salmonid, non-salmonid and marine fish. In contrast to typical $A$. salmonicida the atypical strains comprise a heterogeneous group in terms of molecular and phenotypic characteristics (reviewed in Wiklund \& Dalsgaard 1998). However, the genetic diversity demonstrated among atypical strains of $A$. salmonicida using various molecular methods (Hänninen \& Hirvelä-Koski 1997, Umelo \& Trust 1998, Høie et al. 1999, O'hIci et al. 2000, Lund et al. 2002) cannot be related to specific genes. Genes of interest for both virulence and epidemiological studies include the hydrophobic A-protein subunit of the surface A-layer. A correlation between the surface A-layer and virulence has been suggested (Kay et al. 1981, Austin \& Austin 1993). However, virulent strains with no detectable Alayer and non-virulent strains possessing an A-layer have been reported (Ellis et al. 1988, Olivier 1990, Austin \& Austin 1993). The A-layer is also reported to protect the bacteria from the bactericidal activity of both immune and non-immune serum and probably also from the killing activity of phagocytic cells (reviewed in Secombes \& Olivier 1997).

The A-protein is encoded by the virulence array protein gene A $(\operatorname{vap} A)$. The $\operatorname{vapA}$ gene of an Aeromonas salmonicida ssp. salmonicida strain has been sequenced and the deduced A-protein sequence consists of 502 amino acids including a 21 amino acid signal peptide (Chu et al. 1991; GenBank accession number M64655). The A-proteins of 4 atypical strains of A. salmonicida were shown to have a sequence similarity of 90 to $94 \%$ compared to the typical reference sequence M64655 (Lund et al. 2003b). Most of the A-protein sequence is highly conserved, apart from a region between residues 90 and 180. To assess the genetic diversity of Aproteins, the vapA genes of an additional 19 typical and atypical strains of $A$. salmonicida were sequenced.

The Aeromonas salmonicida strain collection used in this study comprises type strains of the subspecies salmonicida, masoucida, achromogenes and smithia, in addition to atypical strains from spotted wolffish Anarhichas minor, cod Gadus morhua, halibut Hippoglossus hippoglossus, turbot Scophthalmus maximus, char Salvelinus alpinus, flounder Platichthys flesus, and roach Rutilus rutilus (Table 1). The achromogenes type strains ATCC 33659 and NCIMB 1110 have identical origin according to information from 
Table 1. Aeromonas salmonicida. Strain designation, host data and isolation location

\begin{tabular}{|c|c|c|c|c|}
\hline A. salmonicida subspecies & Strain no. & Designation & Host & Country of origin \\
\hline salmonicida & M64655 & $\mathrm{A} 450$ & & \\
\hline salmonicida & 4004-Ass & 429-R CAE-144 & Atlantic salmon Salmo salar & Canada \\
\hline salmonicida & 4010-Ass & NCIMB 1102 & Atlantic salmon Salmo salar & UK \\
\hline salmonicida & 4012-Ass & МТ028 & Atlantic salmon Salmo salar & Scotland \\
\hline salmonicida & 4014-Ass & $88 / 09 / 1920$ & Atlantic salmon Salmo salar & Norway \\
\hline salmonicida & 4017-Ass & $3329 / 89$ & Atlantic salmon Salmo salar & Norway \\
\hline masoucida & 4035-Asm & ATCC 27013 & Masou salmon Oncorhynchus masou & Japan \\
\hline masoucida & 4110-Asm & ATCC 27013 & Masou salmon Oncorhynchus masou & Japan \\
\hline achromogenes & 4036-Asa & ATCC 33659 & Brook trout Salmo trutta & UK \\
\hline achromogenes & 4111-Asa & NCIMB 1110 & Brook trout Salmo trutta & UK \\
\hline smithia & 4109-Assm & NCIMB 13210 & Roach Rutilus rutilus & UK \\
\hline atypical & 4048 & $99 / 92$ & Spotted wolffish Anarhichas minor & Norway \\
\hline atypical & 4065 & K-0698 & Spotted wolffish Anarhichas minor & Norway \\
\hline atypical & 4067 & K-9/98 & Spotted wolffish Anarhichas minor & Norway \\
\hline atypical & 4088 & $92 / 09 / 1777$ & Spotted wolffish Anarhichas minor & Norway \\
\hline atypical & 4128 & F 98/01 & Spotted wolffish Anarhichas minor & Norway \\
\hline atypical & 4129 & $\mathrm{~V}-01 / 1001$ & Spotted wolffish Anarhichas minor & Norway \\
\hline atypical & 4050 & $104 / 95$ & Halibut Hippoglossus hippoglossus & Norway \\
\hline atypical & 4097 & $\mathrm{~T}-01 / 0900$ & Halibut Hippoglossus hippoglossus & Norway \\
\hline atypical & 4092 & $88 / 09 / 02778$ & Turbot Scophthalmus maximus & Norway \\
\hline atypical & 4099 & $93 / 09 / 914$ & Cod Gadus morhua & Norway \\
\hline achromogenes & 4102 & Olivier;81377 & Cod Gadus morhua & Canada \\
\hline achromogenes & 4043 & $117-92$ & Char Salvelinus alpinus & Finland \\
\hline atypical & 4122 & $26-\mathrm{F}-16-4$ & Flounder Platichthys flesus & Finland \\
\hline
\end{tabular}

the culture collections, but in our strain collection are designated 4036-Asa and 4111-Asa, respectively. Similarly, the masoucida subspecies 4035-Asm used in our laboratory and the strain 4110-Asm derived from Institute for Experimental Pathology, Iceland, have a common origin in type strain ATCC 27013 (Table 1).

The A-protein sequences were deduced from the vapA gene sequences obtained by primer walking of 1565 bp PCR-products as described by Lund et al. (2003b). The nucleotide sequences of 15 vapA genes representing A-protein diversity have accession numbers from AJ749879 to AJ749893. Multiple alignment of the predicted protein sequences was produced using Clustal X (1.8) (Thompson et al. 1997), and an unrooted similarity dendrogram based on sequence comparison was derived by the bootstrap neighbour joining method (Felsenstein 1985).

The similarity of the A-protein sequences is at least $92 \%$ at the nucleotide level and $85 \%$ at the amino acid level, and the number of amino acids varies from 501 to 507. Multiple alignment of the A-protein sequences reveals highest variability in amino acids in the region between residues 90 to 180 (Fig. 1), where amino acids are substituted, inserted or deleted compared to the reference sequence M64655. However, the C-terminal region of approximately 140 residues is highly conserved. For unknown reasons, all sequenced strains have phenylalanine (F) and leucine (L) in position 471 and 472 compared to leucine (L) and valine (V), respectively, in the reference sequence.

The A-protein sequences of the 5 Aeromonas salmonicida ssp. salmonicida strains sequenced in this study are identical, except for strain 4012 (AJ749882) that has the glutamate (E) in position 124 substituted with lysine $(\mathrm{K})$.

The vapA nucleotide sequences of the masoucida strains 4035-Asm and 4110-Asm, both originating from ATCC 27013, are identical, including a deletion of a 56 nucleotide sequence (AJ749883). Whether the culture

Fig. 1. Multiple alignment of A-protein sequences deduced from nucleotide sequences of virulence array protein gene A (vapA) of Aeromonas salmonicida strains from various fish species, including the subspecies strains salmonicida (4004-Ass, 4010-Ass, 4012-Ass, 4014-Ass and 4017-Ass), masoucida (4110-Asm), achromogenes (4036-Asa and 4111-Asa) and smithia (4109-Assm). The A-protein sequence of a typical A. salmonicida strain (GenBank M64655) is used as reference, and residues identical to the reference sequence have been replaced with dots (.). In the consensus line positions with a fully conserved residue, or strong or weaker groups fully conserved are indicated with $(*),(:)$ or $($.$) , respectively. Due to amino acid insertions and deletions in the$ atypical strains, the residue positions are different from those used in GenBank. The C-terminal end of the A-protein of strains 4043, 4048, 4050 and 4065 was not sequenced. sw.fish: spotted wolffish 
M64 655

4004-Ass

4010-Ass

4012-Ass

4014-Ass

4017-Ass

4035-Asm

4110-Asm

4036-Asa

4111-Asa

4048-sw. fish

4065-sw. fish

4067-sw. fish

4088-sw. fish

4128-sw. fish

4129-sw. fish

4050-halibut

4097-halibut

4092-turbot

4099-cod

$4102-\mathrm{cod}$

4043-char

4122-flounder

4109-Assm

Consensus

M64655

4004-Ass

4010-Ass

4012-Ass

4014-Ass

4017-Ass

4035-Asm

4110-Asm

4036-Asa

4111-Asa

4048-sw. fish

4065-sw. fish

4067-sw. fish

4088-sw. fish

4128-sw. fish

4129-sw. fish

4050-halibut

4097-halibut

4092-turbot

4099-cod

4102-cod

4043-char

4122-flounder

4109-Assm

Consensus

M64655

4004-Ass

4010-Ass

4012-Ass

4014-Ass

4017-Ass

4035-Asm

4110-Asm

4036-Asa

4111-Asa

4048-sw. fish

4065-sw. fish

4067-sw. fish

4088-sw. fish

4128-sw. fish

4129-sw. fish

4050-hal ibut

4097-halibut

4092-turbot

4099-cod

$4102-\operatorname{cod}$

4043-char

4122-flounder

4109-Assm

Consensus

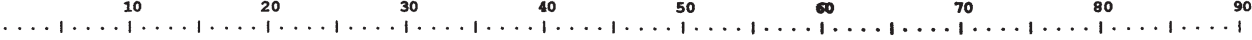
MFKKTLI AAAIVVGSAAPAFADVVI SPNDNT FVTTSLASVTKQPVLDFSTAQQNLTLNFSEVGDLKNNGFIVLEIQGEGQFNDAEIRQWL

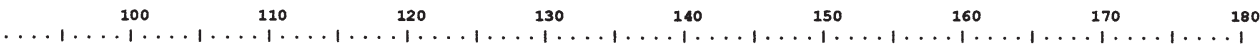
SNGFWRR PFTGLLVNPND----HGNF- -ANSGEVNDVRKFFKI ISDGTQLT IVHTIDSNGKR LRLALASDVEET INFADAEVE LKLNLA

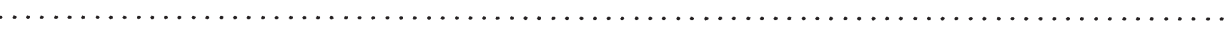

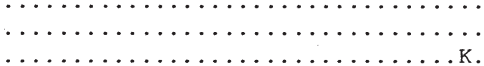

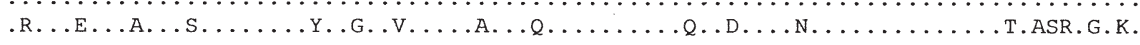

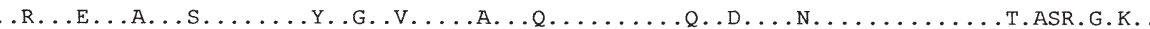

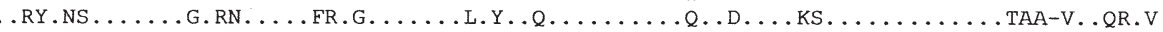

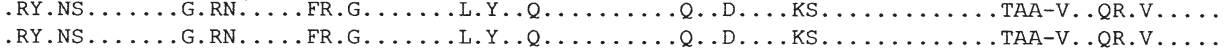

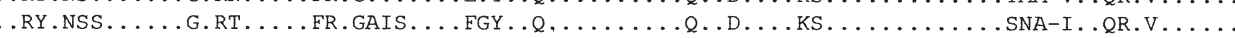

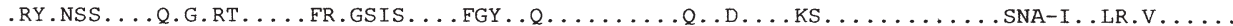

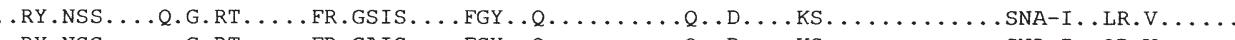

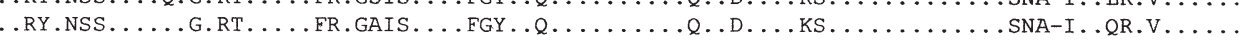

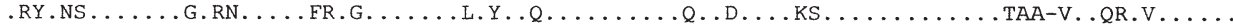

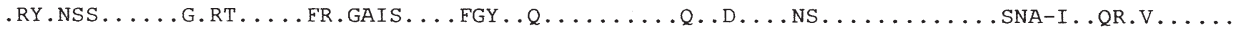

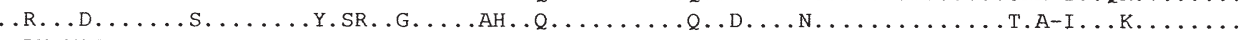

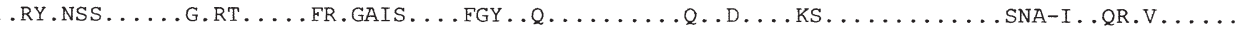

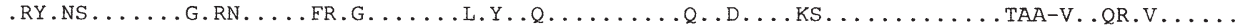

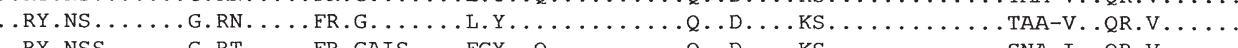

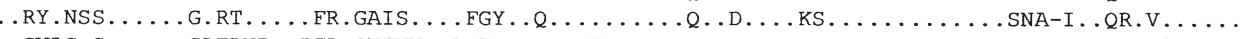

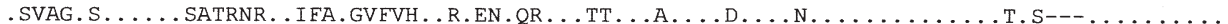

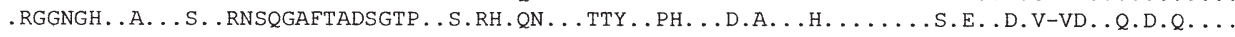

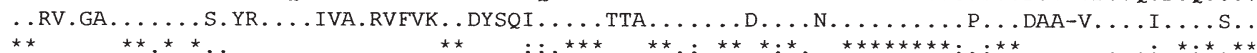

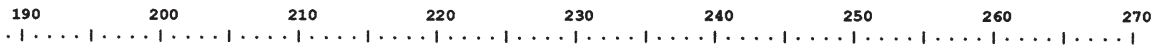
NQAFKLTSGSQGTVALTAGALWNASYTADPVATKPLFKLGKLFQLSLTNAGKATALVSEGFLKLNI GDANISATDFAITNVTTNQTI QRD

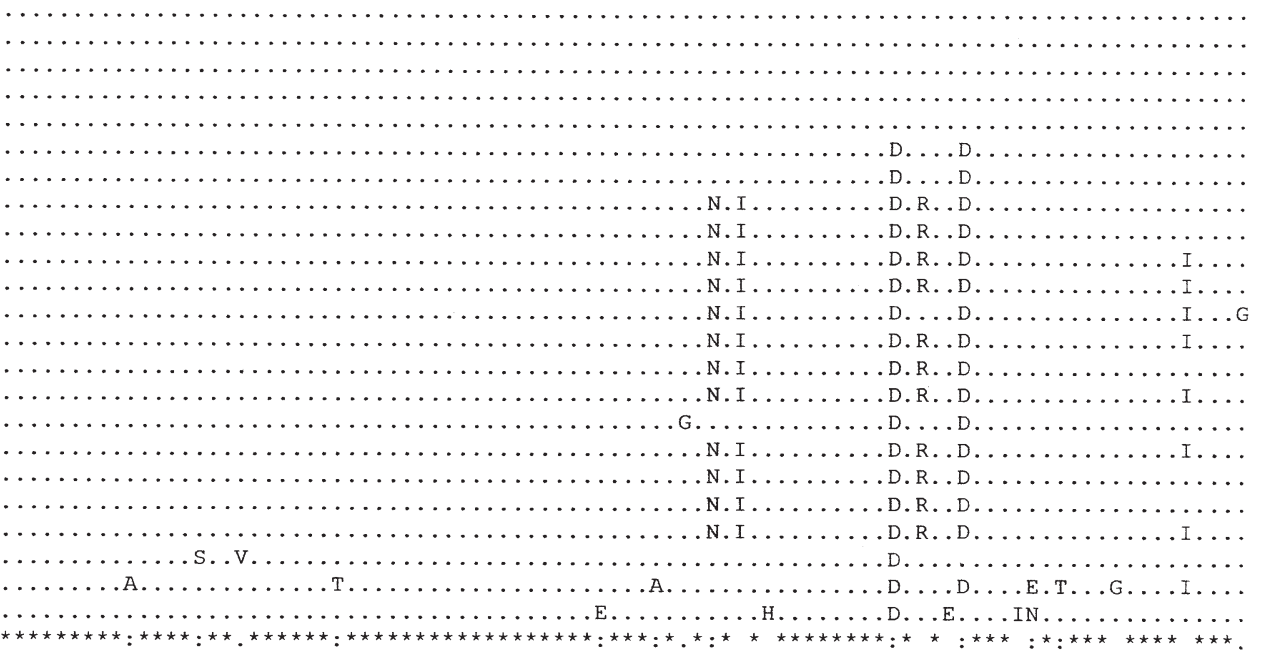

Fig. 1 (continued on next page) 
M64655

4004-Ass

4010-Ass

4012-Ass

4014-Ass

4017-Ass

4035-Asm

4110-Asm

4036-Asa

4111-Asa

4048-sw. fish

4065-sw. fish

4067-sw. fish

4088-sw. fish

4128-sw. fish

4129-sw. fish

4050-halibut

4097-halibut

4092-turbot

4099-cod

4102-cod

4043-char

4122-flounder

4109-Assm

Consensus

M64655

4004-Ass

4010-Ass

4012-Ass

4014-Ass

4017-Ass

4035-Asm

4110-Asm

4036-Asa

4111-Asa

4048-sw. fish

4065-sw. fish

4067-sw. fish

4088-sw. fish

4128-sw. fish

4129-sw. fish

4050-halibut

4097-halibut

4092-turbot

4099-cod

4102-cod

4043-char

4122-flounder

4109-Assm

Consensus

M64 655

4004-Ass

4010-Ass

4012-Ass

4014-Ass

4017-Ass

4035-Asm

4110-Asm

4036-Asa

4111-Asa

4048-sw. fish

4065-sw. fish

4067-sw. fish

4088-sw.fish

4128-sw.fish

4129-sw.fish

4050-halibut

4097-hal ibut

4092-turbot

4099-cod

$4102-\operatorname{cod}$

4043-char

4122-flounder

4109-Assm

Consensus

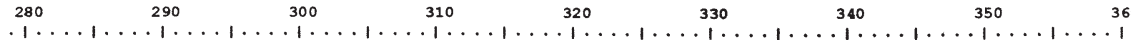
KVNLTLTGDVSAFKKDANGNLVNKAGASIGWKAAADGQSATAVLGAGNMAGGVQNALAAFGT LYVAADNTVPVPAVN FNVKAE IQGDSQA

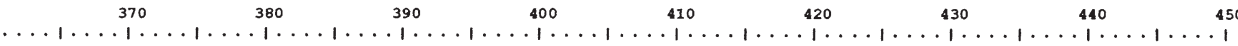
TYNY FKDELADL FI LTRDGMKFDT ITTGTTSANLIH I RDVSN I LPTEGGKI FVTI TEYADHAANGRGEGTVLVTRKALSVTLPSGGAVTL

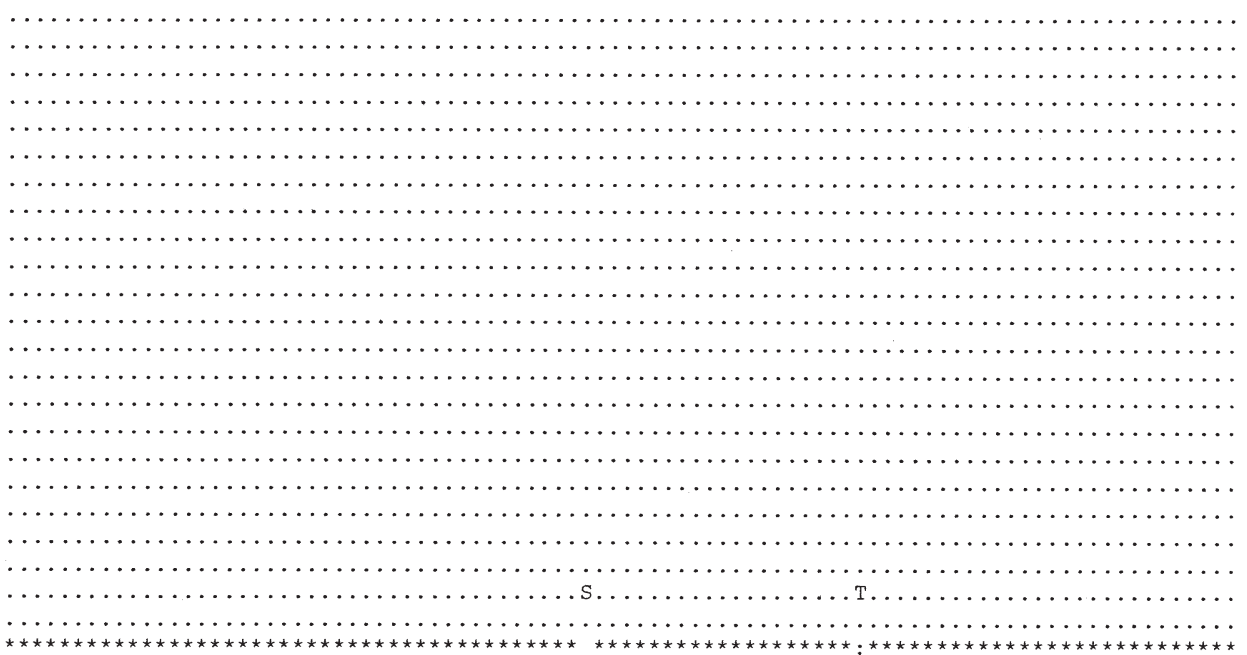

$\ldots 1 \ldots 1 \ldots 1 \ldots 1 \ldots 1 \ldots 1 \ldots 1 \ldots 1 \ldots 1 \ldots 1 \ldots 1 \ldots 1 \ldots 1 \ldots$

KPADVAADVGAS ITAGRQARLVEEVETNQGEVAVKKSNAEGVDIONGTRGTAPLVDETI

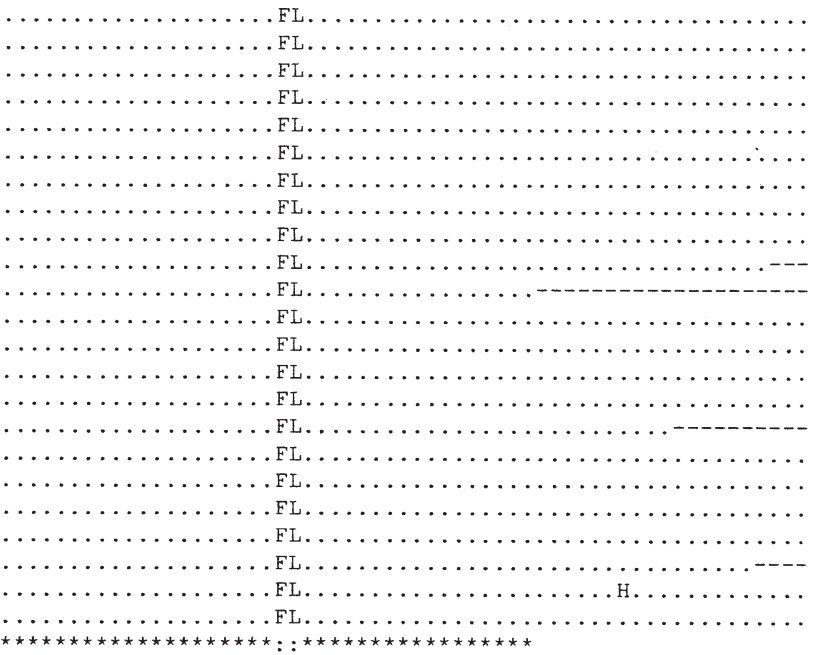

Fig. 1 (continued) 
collection contains a masoucida type strain with a deletion in the vapA gene or identical deletions have occurred in 2 different laboratories, is unknown. These strains do not express the surface A-layer as demonstrated by lack of binding of A-protein-specific antibodies to cell lysate on Western blot (not shown). The lack of A-layer is probably a result of the translation being out of the reading frame downstream of the deletion. For comparison, the deduced A-protein sequence is adjusted to correct the reading frame, resulting in 19 residues missing in the $\mathrm{N}$-terminal region of the protein (Fig. 1). In addition to the deletion, the masoucida strains differ from the reference sequence M64655 by having 28 amino acids substituted.

A deletion probably starting upstream of the start codon was detected in the vapA gene of the 4036-Asa of the achromogenes type strain (ATCC 33659, AJ749888), and as in the masoucida strains, this strain does not express the surface A-layer. In spite of the identical origin, the deletion is not present in the achromogenes strain 4111-Asa (NCIMB 1110, AJ749889), and it is unknown when the deletion has occurred. Apart from the deletion, the achromogenes strains have identical nucleotide and amino acid sequences. However, they differ from the reference sequence M64655 in that they have 33 amino acids substituted and, as in most of the atypical strains, the asparagine $(\mathrm{N})$ in position 167 is deleted. The A-proteins of the smithia type strain 4109-Assm and the atypical strains from char (4043) and flounder (4122) have in addition the valine (V) in position 62 deleted. Furthermore, several of the atypical strains have from 2 to 7 amino acids inserted between positions 108 to 120 .
Although the highest amino acid variability is detected between residues 90 and 180, most of the atypical strains also have an additional 10 to 15 amino acids substituted outside this region. Compared to the reference sequence M64655, half of the substitutions involve changes between hydrophilic and hydrophobic amino acids that may alter the hydrophobicity and the surface A-protein.

A similarity dendrogram based on multiple alignment of the A-protein sequences available for all strains, i.e. between position 44 and 489, is shown in Fig. 2. The strains appear in 3 different clusters, with all the subspecies salmonicida strains in 1 cluster, and the masoucida type strains together with a strain from halibut (4050) in another. The third cluster contains the achromogenes type strains together with 10 atypical strains from the fish species cod, turbot, halibut and spotted wolffish, while the smithia type strain (4109) and the char and flounder strains (4043 and 4122) are unclustered.

The impact of the molecular variation in the A-proteins on the properties of the surface A-layer of the various atypical Aeromonas salmonicida strains is not known. The conserved regions are probably important for folding of the A-protein, assembling and anchoring of the surface A-layer to the membrane, while the variable region may affect the A-layer as a virulence factor. A study of the surface topography of the A-layer revealed that the conserved $\mathrm{C}$-terminal region contained most of the surface-accessible sequences, while the N-terminal region contained the majority of the inaccessible residues (Doig et al. 1993). However, 65 surface-accessible residues in 5 linear epitopic clusters, of which 3 appear to be within the revealed variable region between residues 90 to 180 , were

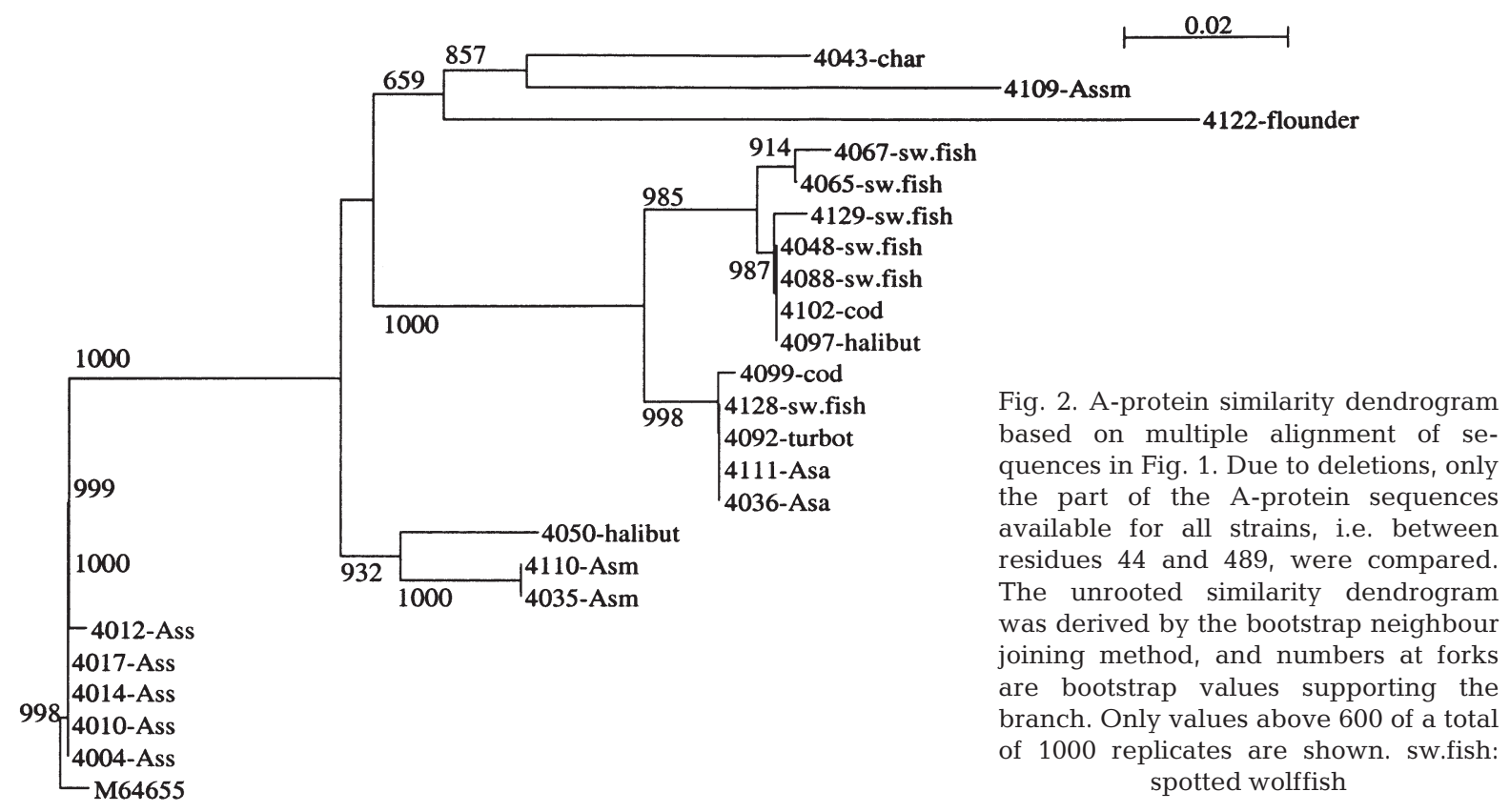


dispersed approximately between residues 30 and 240 . Thus, most of the A-protein sequence variability appears to be restricted to a predicted surface exposed and immunogenic region, which we believe may result in antigenic differences among the atypical strains. This is supported by the fact that although a polyclonal antiserum raised against a typical A. salmonicida strain and adsorbed with atypical strains resulted in a great reduction of the titre, significant reactivity remained, indicating antigenic differences between the atypical and typical strains (Doig et al. 1993). Further, an A-protein-specific monoclonal antibody was shown to react with a restricted number of atypical strains of A. salmonicida (Lund et al. 2003b). However, as demonstrated in our A-protein sequences, the C-terminal region appears to be very conserved as 8 different monoclonal antibodies specific to this region of the A-protein reacted with all 25 typical and atypical strains of A. salmonicida studied (Doig et al. 1993).

Our interest in the surface A-layer is related to its possible role as a protective antigen in furunculosis vaccines. In oil-adjuvanted furunculosis vaccines for salmon, the A-layer appeared to be important, since vaccines containing strains without A-layer did not provide any protection (Lund et al. 2003a). Also, vaccines based on atypical Aeromonas salmonicida strains from the 3 different clusters shown in Fig. 2 showed significant differences in protection of spotted wolffish when challenged with strain 4067 (Lund et al. 2003b). Today, atypical furunculosis in farmed marine fish species is an increasing problem. Vaccination with the very efficient furunculosis vaccines for salmon appears to give poor protection against infection with atypical A. salmonicida in halibut farms in Norway (K. Gravningen pers. comm.). Thus, if the A-protein is a protective antigen, the vaccine efficacy may depend on the antigenic similarity between the vaccine and the infecting strain.

Acknowledgements. This study was supported by The Norwegian Industrial and Regional Development Fund (SND) in addition to funding from Fiskeriforskning. The control sequencing of some of the strains by Dr. Duncan Colquhoun, National Veterinary Institute of Norway, is gratefully appreciated.

\section{LITERATURE CITED}

Austin B, Austin DA (1993) Aeromonadaceae representatives (Aeromonas salmonicida). In: Austin B, Austin DA (eds) Bacterial fish pathogens disease in farmed and wild fish, 2nd edn. Ellis Horwood, Chichester, p 86-170

Austin DA, McIntosh D, Austin B (1989) Taxonomy of fish associated Aeromonas spp., with the description of Aeromonas salmonicida ssp. smithia ssp. nov. System Appl Microbiol 11:277-290

Chu S, Cavaignac S, Feutrier J, Phipps BM, Kostrzynska M, Kay WW, Trust TJ (1991) Structure of the tetragonal surface virulence array protein and gene of Aeromonas salmonicida. J Biol Chem 266:15258-15265

Doig P, McCubbin WD, Kay CM, Trust TJ (1993) Distribution of surface-exposed and non-accessible amino acid sequences among the two major structural domains of the S-layer protein of Aeromonas salmonicida. J Mol Biol 233:753-765

Ellis AE, Burrows AS, Stapleton KJ (1988) Lack of relationship between virulence of Aeromonas salmonicida and the putative virulence factors: A-layer, extracellular proteases and extracellular haemolysin. J Fish Dis 11:309-323

Felsenstein J (1985) Confidence limits on phylogenies: an approach using bootstrap. Evolution 39:783-791

Hänninen ML, Hirvelä-Koski V (1997) Molecular and phenotypic methods for the characterization of atypical Aeromonas salmonicida. Vet Microbiol 56:147-158

Høie S, Dalsgaard I, Aase IL, Heum M, Thornton JM, Powell R (1999) Polymerase chain reaction (PCR)-based typing analysis of atypical isolates of the fish pathogen Aeromonas salmonicida. System Appl Microbiol 22:403-411

Kay W, Buchley JT, Ishiguro EE, Phipps BM, Monette JPL, Trust TJ (1981) Purification and disposition of a surface protein associated with virulence of Aeromonas salmonicida. J Bacteriol 147:1077-1084

Kimura T (1969) A new subspecies of Aeromonas salmonicida as an etiological agent of furunculosis on 'sakuramasu' (Oncorhynchus masou) and pink salmon (O. gorbuscha) rearing for maturity. Part 1 . On the morphological and physiological properties. Fish Pathol 3:34-44

Lund V, Jenssen LM, Wesmajervi MS (2002) Assessment of genetic variability and relatedness among atypical Aeromonas salmonicida from marine fishes, using AFLPfingerprinting. Dis Aquat Org 50:119-126

Lund V, Arnesen JA, Coucheron D, Modalsli K, Syvertsen C (2003a) The Aeromonas salmonicida A-layer protein is an important protective antigen in oil-adjuvanted vaccines. Fish Shellfish Immunol 15:367-372

Lund V, Espelid S, Mikkelsen H (2003b) Vaccine efficacy in spotted wolffish (Anarhichas minor O.) related to molecular variation in the A-layer protein of atypical Aeromonas salmonicida. Dis Aquat Org 56:31-42

Lund V, Jenssen LM, Wesmajervi MS (2002) Assessment of genetic variability and relatedness among atypical Aeromonas salmonicida from marine fishes, using AFLPfingerprinting. Dis Aquat Org 50:119-126

O'hIci B, Olivier G, Powell R (2000) Genetic diversity of the fish pathogen Aeromonas salmonicida demonstrated by random amplified polymorphic DNA and pulsed-field gel electrophoresis analyses. Dis Aquat Org 39:109-119

Olivier G (1990) Virulence of Aeromonas salmonicida: lack of relationship with phenotypic characteristics. J Aquat Anim Health 2:119-127

Pavan ME, Abbott SL, Zorzopulos J, Janda JM (2000) Aeromonas salmonicida subsp pectinolytica subsp nov., a new pectinase-positive subspecies isolated from a heavily polluted river. Int J System Bacteriol 50:1119-1124

Secombes CJ, Olivier G, (1997) Host-pathogen interactions in salmonids. In: Bernoth EM, Ellis AE, Midtlyng PJ, Olivier G, Smith P (eds) Furunculosis - multidiciplinary fish disease research. Hartnolls Ltd, Bodmin, p 269-296

Smith IW (1963) The classification of Bacterium salmonicida. J Gen Microbiol 33:263-274

Thompson JD, Gibson TJ, Plewniak F, Jeanmougin F, Higgins DJ (1997) The ClustalX windows interface: flexible strategies for multiple sequences alignment aided by quality analysis tools. Nucleic Acids Res 24:4876-4882

Umelo E, Trust TJ (1998) Physical map of the chromosome of Aeromonas salmonicida and genomic comparisons between Aeromonas strains. Microbiology UK 144:2141-2149

Wiklund T, Dalsgaard I (1998) Occurrence and significance of atypical Aeromonas salmonicida in non-salmonid fish species: a review. Dis Aquat Org 32:49-69 